\title{
O Papel da Frequência Fundamental e da Jntensidade para Distinguir Enunciados Jnterrogativos de Afirmativos na Região Nuclear do Dialeto Curitibano
}

The Role of F0 And Intensity in Distinguishing Yes/No Questions from Neutral Statements in the Nuclear Region of the Dialect of People from Curitiba

\section{Pollianna MILAN* Denise Cristina KLUGE**}

Resumo: Este estudo pretende testar se os parâmetros acústicos frequência fundamental e intensidade ajudam a distinguir uma afirmação de uma pergunta no dialeto curitibano. Trata-se de uma pesquisa voltada para a área da prosódia, com o objetivo de descrever como estes traços prosódicos exercem papel de distinção nos enunciados afirmativos e interrogativos. Para a obtenção do corpus contamos com a gravação de dois informantes nascidos em Curitiba, um homem e uma mulher, e adotamos a metodologia do projeto Atlas Multimídia Prosódico do Espaço Românico do Português (Amper-Por), do qual a pesquisa é filiada. A partir dos dados analisados, podemos concluir que os dois parâmetros acústicos têm papel importante na distinção de

\footnotetext{
* Doutoranda do Programa de Pós-Graduação em Letras - Estudos Linguísticos pela Universidade Federal do Paraná (UFPR). Mestre pela mesma instituição, na área de Estudos Linguísticos, Prosódia (2015).

** Doutora em Letras (Inglês e Literatura Correspondente) pela Universidade Federal de Santa Catarina (UFSC, 2009). Mestre em Letras (Inglês e Literatura Correspondente) pela UFSC (2004). Professora Adjunta da Universidade Federal do Paraná no Departamento de Letras Estrangeiras Modernas e no Programa de Pós-Graduação em Letras da UFPR.
} 
modalidades. Os valores de frequência fundamental entre afirmações e interrogações são significativamente diferentes principalmente nas sílabas prétônicas e algumas tônicas. A intensidade também manteve padrões diferentes, com valor significativamente distinto para as sílabas pré-tônicas das palavras oxítonas, nas pré-tônicas e tônicas das paroxítonas e nas pré-tônicas, tônicas e últimas pós-tônicas das proparoxítonas. Concluímos, assim, que a frequência fundamental e a intensidade são dois traços prosódicos importantes na hora de distinguir quando um falante afirma algo e quando ele faz uma pergunta. Palavras-chave: Prosódia. Frequência fundamental e intensidade. Dialeto de Curitiba.

Abstract: This study aims at investigating whether acoustical parameters such as F0 and intensity have a role in distinguishing neutral statements from neutral yes/no questions of the dialect of people from Curitiba, Paraná. For the corpus, two informants (a woman and a man) who were born in Curitiba were recorded following the methodology of the project Multimedia Prosodic Atlas for Romance Languages - Portuguese (AMPER-POR) to which the present research is link to. Based on the analysis of the data, it was possible to conclude that both acoustical parameters play a role in distinguishing the sentences. The values for F0 comparing yes/no questions and neutral sentences are significantly different mainly in the pre-tonic syllables and some of the postonic. Intensity has also shown different patterns with significantly different values for pre-tonic syllables of the oxytones, pre-tonic and tonic syllables of the paroxytones and for pre-tonic, tonic and pos-tonic syllables of the proparoxytones. It can be concluded that $\mathrm{F} 0$ and intensity are two important prosodic features in order to distinguish a statement from a yes/no question. Keywords: Prosody. F0 and e intensity. Dialect from Curitiba.

\section{Introdução}

Prosodicamente falando, o que distingue uma pergunta de uma afirmação? Os parâmetros acústicos intensidade e frequência fundamental podem ser considerados bons aliados nesta distinção? A partir destes questionamentos, este estudo pretende analisar em que aspectos a intensidade 
e a frequência fundamental colaboram com a fala na hora de o locutor elaborar um enunciado interrogativo ou fazer uma asserção. Para isso, utilizamos o corpus do projeto Atlas Multimídia Prosódico do Espaço Românico do Português (doravante Amper-Por), do qual somos filiadas, para coletar dados da fala de curitibanos.

Nesta pesquisa, consideramos afirmativas neutras aquelas pronunciadas por locutores da maneira mais imparcial possível, sem a presença de ironia, por exemplo. Já as interrogativas totais foram consideradas aquelas em que comportam como resposta apenas um sim ou um não. Nos debruçamos na análise da região nuclear das sentenças, o que quer dizer que avaliamos nas frases, sintaticamente falando, o conteúdo que está após o verbo, ou seja, o seu final ou sintagma verbal. Escolhemos apenas a região nuclear porque estudos como o de Moraes (2008) demonstraram que é apenas nesta região que está a principal distinção entre modalidades, ou seja, entre uma afirmação e uma interrogação. Importante explicar que usaremos o termo modalidade para nos referirmos às interrogativas totais e às declarativas neutras como contornos de variação melódica do português brasileiro. O termo foi retirado dos conceitos de Fónagy (1993, p. 25) de que a prosódia pode ser reduzida à função modal, ou seja, dos modos de enunciação (interrogativo, declarativo, imperativo, exclamativo). O termo modalidade também é usado por Moraes (2008) para se referir às funções da entoação conhecidas como o uso de atitudes dos falantes.

Começamos, neste artigo, fazendo uma discussão sobre os termos prosódia e entoação; passamos à metodologia e testes estatísticos para, enfim, apresentarmos os resultados.

\section{A Relação entre Prosódia e Entoação}

Nos propomos a começar este artigo com uma breve discussão sobre prosódia e entoação, já que a frequência fundamental e a intensidade são parâmetros acústicos relacionados a elas. A tarefa de distinguir os dois termos, porém, não é fácil e nem sempre bem-sucedida. Hirst e Di Cristo (1998) são dois dos autores que propõem esta diferenciação.

Tanto o termo prosódia como o termo suprassegmento, por exemplo, podem ser usados em um sentido largo, incluindo fatores como acento, tom 
e quantidade, que fazem parte essencial da identidade lexical das palavras. Já o termo entoação, num primeiro momento, pode ser usado num sentido mais estreito, classificado como algo não lexical, com características como pitch, declinação e fenômenos de fronteira (HIRST; DI CRISTO, 1998, p. 4).

Antes de prosseguirmos na relação entre prosódia e entoação, porém, gostaríamos de explicitar melhor o que os autores definem como itens lexicais e não lexicais. Hirst e Di Cristo (1998) classificam acento, tom e quantidade como itens lexicais baseados em línguas como o alemão e o grego, que fazem a distinção lexical das palavras a partir desses três itens. Isso ocorre também no português brasileiro para pares como "caqui" e "cáquii", em que os três parâmetros (tom, acento e quantidade) também são os responsáveis por marcar a distinção das duas palavras. Contudo, os autores apontam que esta questão pode ser um problema, pois nem todas as línguas funcionam dessa maneira.

O item não lexical, por sua vez, refere-se a alterações no enunciado, como o próprio nome diz, que independem do léxico das palavras, ou seja, em muitas línguas - como no português brasileiro - sabe-se que a curva entoacional interrogativa terá um momento de ascensão na região nuclear (no final da sentença), independentemente do léxico presente nesta região, o que quer dizer que não importa, neste caso, segundo os autores, o tom, o acento e a quantidade, a curva subirá de qualquer maneira.

Desse ponto de vista, Hirst e Di Cristo (1998) classificam, então, a prosódia como algo lexical e a entoação como algo não lexical. Para entender, também, um segundo tipo de ambiguidade que existe no uso dessas palavras, é preciso compreender, primeiramente, a distinção entre dois níveis: (i) o nível físico ou da implementação (observável e mensurável com parâmetros acústicos) e (ii) o nível formal (linguístico) ou da representação, que é a abstração de um modelo criado para descrever as propriedades fonológicas da prosódia.

o nível linguístico abstrato tenta explicar a competência linguística de um falante, o conhecimento linguístico que se presume que ele possua. No nível físico, a entoação é usada para se referir a variações de um ou mais parâmetros acústicos. Destes, a F0 (frequência fundamental) é 
universalmente conhecida por ser o principal parâmetro ${ }^{1}$ (HIRST; DI CRISTO 1998, p. 4, tradução nossa).

Para estes pesquisadores, qualquer tentativa de descrever a entoação no nível físico implica, também, em descrevê-la no nível formal abstrato (e linguístico) e não lexical.

Com o intuito de sintetizar este pensamento, Hirst e Di Cristo propuseram o seguinte esquema, ilustrado na Figura 1, lembrando que os parâmetros linguísticos e físicos e os parâmetros lexicais e não lexicais não são totalmente independentes:

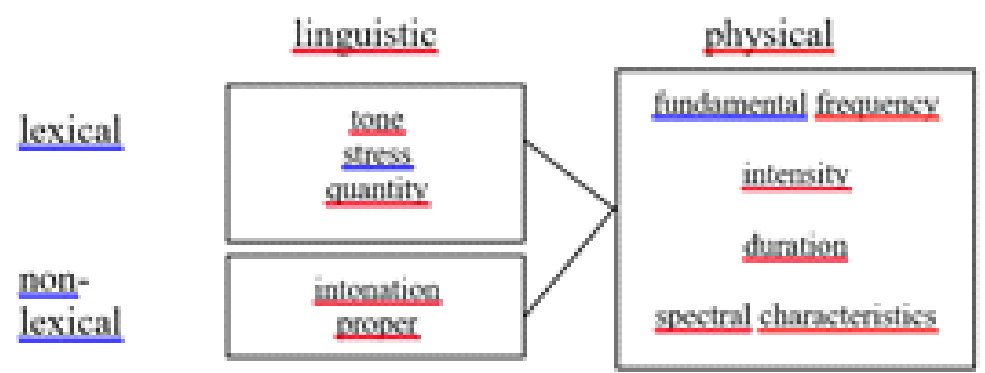

Fonte: Hirst e Di Cristo (1998, p. 5).

Figura 1 - Esquema que propõe a entoação como elemento linguístico e não lexical

É possível interpretar, a partir da Figura 1, que a relação entre os níveis físico e linguístico pode ser mais óbvia quando há uma separação entre os dados acústicos - obtidos através de uma análise espectrográfica e entre os dados criados a partir, por exemplo, de uma transcrição fonológica linguística -, como sobre a movimentação dos tons em um enunciado. A

1 "the abstract linguistic level attempts to account for a speaker's linguistic competence, the implicit knowledge about the language which he is assumed to possess. On the physical level, intonation is used to refer to variations of one or more acoustic parameters. Of these, fundamental frequency $(F 0)$ is universally acknowledged to be the primary parameter". 
discussão sobre a inter-relação entre as características prosódicas abstratas e os traços acústicos, porém, mostra-se longe de ser simples. Uma maneira encontrada por Hirst e Di Cristo (1998) para explicar melhor isso é usando o conceito de interface entre fonologia e fonética, com o objetivo de “descrever a relação entre, por um lado, o nível cognitivo da descrição fonológica e, por outro lado, o nível físico da descrição provida por elementos acústicos e fisiológicos"2 (HIRST; DI CRISTO, 1998, p. 6, tradução nossa). Neste caso, o termo prosódia continua sendo utilizado em um sentido largo, para se referir ao sistema cognitivo abstrato (fonológico) e aos parâmetros físicos. Já o termo entoação, neste segundo momento, ganha duas acepções. Uma é que ela é vista como um fato fonético que faria a interface entre o nível fonológico (abstrato) e o nível físico da fala (com cada um de seus elementos). A outra é que a entoação é uma abstração do sistema não lexical, de características fonológicas. Veja na Figura 2:

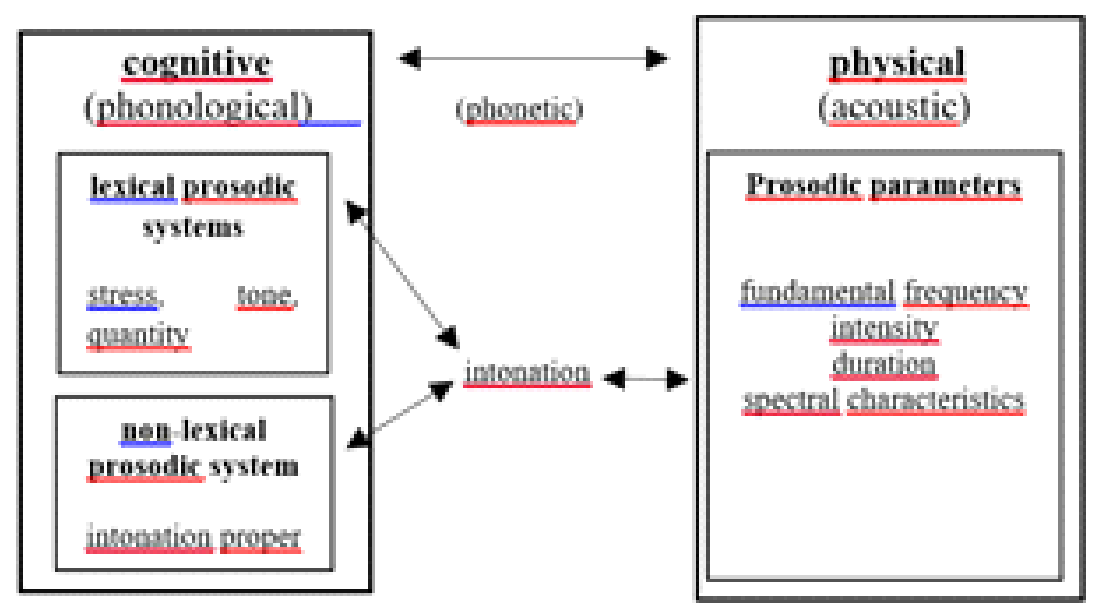

Fonte: Hirst e Di Cristo (1998, p. 7).

Figura 2 - A entoação como item fonológico, mas também fonético, fazendo a interface com os parâmetros acústicos

\footnotetext{
2 "To describe the link between, on the one hand, an abstract, cognitive level of phonological description and, on the other hand, the physical levels of description provided by acoustics and physiology".
} 
A Figura 2 ilustra, mais uma vez, aspectos como acento, tom e quantidade pertencentes ao lexical; frequência fundamental (doravante F0), intensidade, duração e características espectrais como pertencentes aos parâmetros prosódicos e físicos; e, agora, a entoação dividida em duas categorias: aquela como item não lexical que descreve fonologicamente curvas entoacionais, características de pitch e tons de fronteira (no nível representacional); e a entoação fonética, numa segunda acepção, que faz a interface destes parâmetros representacionais com os físicos (no nível da implementação). As setas permanecem em mão dupla porque, ora os falantes se baseiam em pistas físicas para recuperar informações sobre a entoação no nível fonológico (o que inclui tanto a própria entoação, além de itens como acento, quantidade e tom), ora os falantes se baseiam no nível fonológico para recuperar informações do nível físico.

Este posicionamento teórico mostra que o sistema entoacional de uma língua é impossível de ser descrito sem, ao mesmo tempo, dar conta de características prosódicas relevantes, como as do nível acústico, pelo fato de elas serem diretamente observáveis a partir de dados concretos como, por exemplo, os valores de F0, de intensidade e de duração. Por isso, nesta pesquisa, decidimos trabalhar com os parâmetros acústicos de F0 e intensidade para mostrar como eles se comportam no falar de Curitiba, especificamente em enunciados afirmativos neutros (sem juízo de valor, como a ironia) e interrogativas totais (que aceitam como resposta um sim ou um não). Nesse sentido, o estudo trabalha com a segunda acepção de entoação de Hirst e Di Cristo (1998), ou seja, ela como interface entre fonética e fonologia.

Crystal (1975, p. 11) segue uma linha de pensamento parecida com a descrita na Figura 2, ao afirmar que a entoação não é um simples sistema de contornos e níveis, mas um produto de interação (neste caso, a interface representada na Figura 2) de traços do sistema prosódico, como o tom e a duração. Ainda sobre esta linha de raciocínio, Ladd (2008, p. 6) diz que a entoação depende do uso dessas características fonéticas suprassegmentais para expressar significados pragmáticos no nível da sentença de forma linguisticamente estruturada.

Como já explicitado, o presente artigo trabalhará, então, com os parâmetros acústicos de F0 e intensidade. A F0 é medida em Hertz (doravante $\mathrm{Hz}$ ) e corresponde ao número de vezes por segundo em que as pregas 
vocais completam um ciclo de vibração (BOLINGER, 1972, p. 19). O correlato perceptual da F0, então, é chamado de pitch. Muitas vezes traduzido para o português como tom ou inflexão tonal. Ladefoged e Johnson (2006) lembram que muitas línguas usam o pitch para marcar, por exemplo, as fronteiras das unidades sintáticas. "Em quase todas as línguas, a conclusão de uma unidade gramatical, como de um enunciado normal, é sinalizada por um pitch em queda"3 (LADEFOGED; JOHNSON, 2006, p. 254, tradução nossa). A intensidade, por sua vez, medida em decibéis (dB), tem relação com a altura (física) da onda, ou seja, com a amplitude do som e com a energia usada para produzir este som. Ela tem como correlato perceptual o volume (loudness).

\section{Metodologia}

Esta pesquisa está vinculada ao Atlas Multimídia Prosódico do Espaço Românico do Português (doravante Amper-Por). Trata-se de um projeto internacional que chegou ao Brasil sob a coordenação da professora Lurdes de Castro Moutinho, da Universidade de Aveiro (Portugal). O corpus do Amper-Por adaptado para o português brasileiro é o que foi utilizado por nós. A gravação para a obtenção do corpus foi feita da seguinte maneira. Os informantes visualizavam imagens no PowerPoint que, associadas, formavam frases a serem ditas. Antes de começar as gravações, os informantes participaram de um teste de familiarização. Este teste foi montado para que os informantes conhecessem os possíveis personagens (Renato, pássaro, bisavô), suas características (nadador, pateta, bêbado) e de que localidade poderiam ser (Mônaco, Veneza, Salvador). Também foi explicado a eles que a imagem do coração simbolizava o verbo gostar (que deve ser dito sempre na terceira pessoa do singular, no modo presente do indicativo, ou seja, "gosta"). Em seguida, os informantes visualizaram alguns slides montados com os personagens, suas características e o verbo para que pudessem treinar como deveriam dizer os enunciados. $\mathrm{Na}$ Figura 3, por exemplo, temos dois

3 "In nearly all languages, the completion of a grammatical unit such as a normal sentence is signaled by a falling pitch". 
personagens (um homem e um pássaro) separados por um coração. O homem é designado Renato e o coração representa o verbo gostar. Sendo assim, temos a representação da frase "O Renato gosta do pássaro".

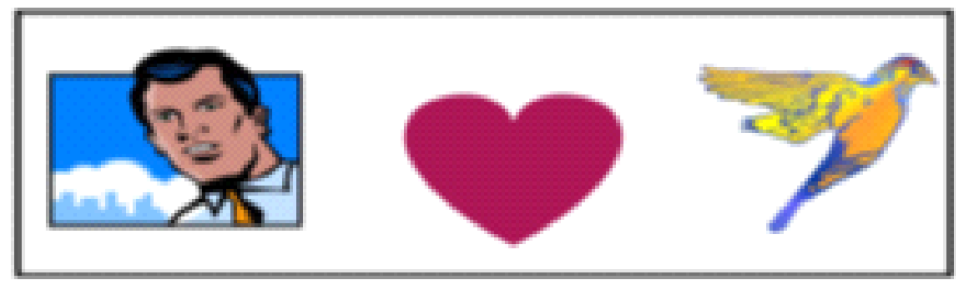

Fonte: Amper-Por.

Figura 3 - Slide do corpus do AMPER-POR para a frase "O Renato gosta do pássaro"

Para formular as interrogativas totais, a única coisa alterada é que o slide recebe um ponto de interrogação antes de todas as imagens e um ponto de interrogação no final delas ${ }^{4}$, como na Figura 4, em que o informante deve dizer "O pássaro gosta do bisavô nadador?".

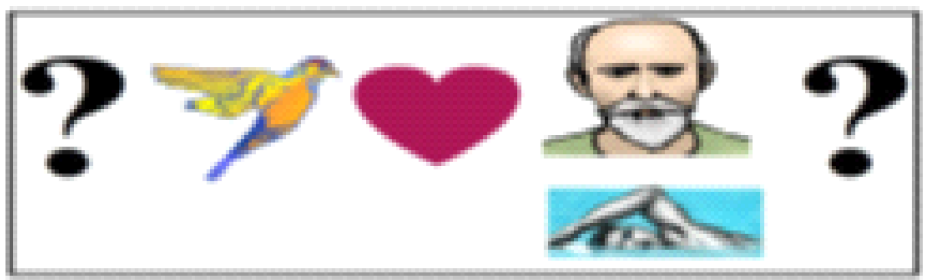

Fonte: Amper-Por.

Figura 4 - Slide do corpus AMPER-POR para o enunciado "O pássaro gosta do bisavô nadador?"

${ }^{4}$ Nunes (2013) modificou os slides das interrogativas totais, acrescentando um ponto de interrogação no início de cada um deles, além do ponto de interrogação no final, porque a autora percebeu que os informantes, quando visualizavam slides sem este ponto de interrogação inicial, costumavam falar o enunciado como se fosse declarativo e, no final, quando se davam conta de que era uma pergunta, mudavam a entoação. 
Assim que os informantes estivessem familiarizados com os enunciados que deveriam falar, começamos oficialmente a gravação das 66 frases que precisavam ser elaboradas após os informantes visualizarem cada um dos 66 slides no PowerPoint.

O corpus conta com diversos tipos de enunciados para a análise da região nuclear. Por isso, dividimos entre as modalidades ${ }^{5}$ (afirmativa e interrogativa total) e por padrão acentual (oxítona, paroxítona e proparoxítona). Por fim, a análise da $\mathrm{F} 0$ e da intensidade se dará também conforme a posição do acento na palavra, a que chamaremos de tonicidade, ou seja, separamos as sílabas em pré-tônicas, tônicas e pós-tônicas.

Dois informantes curitibanos gravaram as sentenças, nos padrões do corpus do AMPER-POR. Um do sexo masculino e um do sexo feminino. Ambos nasceram e sempre viveram em Curitiba (capital paranaense) e se reconhecem como falantes deste dialeto: com grau de escolaridade ensino médio completo. Na época da gravação, ele tinha 24 anos e ela, 23 anos. Os dados foram gravados no mês de março de 2014, em uma cabine com tratamento acústico da Universidade Federal do Paraná (UFPR). Os dados foram gravados em taxa de amostragem de $44.100 \mathrm{~Hz}$, porém esta taxa foi reamostrada para $16.000 \mathrm{~Hz}$, porque este é o valor de amostragem aceito pelo script e pela Interface MatLab AMPER-POR.

Depois da gravação com os informantes, os dados foram abertos no programa Audacity, para que pudéssemos separar frase por frase a ser analisada. As frases foram etiquetadas por sílabas no software Praat e, depois, por meio de um script fornecido pelo Amper-Por, rodamos os dados etiquetados para obter o valor de F0 e de intensidade de cada uma das sílabas das palavras que compunham as frases

Se a frase dita pelo informante fosse "O pássaro gosta do Renato", por exemplo, a palavra da região nuclear seria Renato. Ela foi classificada, então, pelo padrão acentual paroxítono, depois pela tonicidade das sílabas (tônica e suas adjacentes) e, por fim, pela modalidade (afirmativa e interrogativa). Desta mesma maneira procedemos com todas as outras palavras do núcleo, classificando-as. Após o script fornecer os dados de F0 e

\footnotetext{
${ }^{5}$ Grifo nosso.
} 
intensidade de cada sílaba das palavras nucleares, comparamos a diferença de valores entre essas sílabas, segundo a Figura 5.

Exemplo de palavra: RENATO

$\begin{array}{llll} & \begin{array}{l}\text { RE } \\ \text { pré-tônica }\end{array} & \begin{array}{l}\text { NA } \\ \text { tônica }\end{array} & \begin{array}{l}\text { TO } \\ \text { pós-tônica } \\ \text { Afirmativa }\end{array}\end{array}$

Fonte: Amper-Por.

Figura 5 - Esquema que mostra como os dados serão comparados: entre as mesmas sílabas das diferentes modalidades. Neste exemplo, foi usado o parâmetro F0, mas, desta mesma maneira, foi feito com a intensidade

A comparação se deu entre as sílabas de cada modalidade, neste caso entre "RE", "NA" e “TO" (comparação simbolizada pelas flechas largas). Então, comparamos os parâmetros acústicos da sílaba pré-tônica da afirmativa (neste caso $\mathbf{R E}$ ) com a pré-tônica da interrogativa (RE); na sequência, vimos se é significativa a diferença entre os valores destes mesmos parâmetros da tônica da afirmativa e sua correspondente interrogativa (neste caso NA) e, por fím, da pós-tônica (TO) das duas modalidades (esta comparação está simbolizada pelas flechas mais largas na Figura 5).

Seguimos este modelo de análise para a F0 e para a intensidade. Porém, enfrentamos um problema. Como comparar dados de F0 em $\mathrm{Hz}$ sem antes normalizá-los? A literatura da área aponta que é preciso normalizar dados de frequência em Hertz para evitar distorções de valores causadas, muitas vezes, pelas características naturais das pregas vocais de cada falante. Sobre isso, Gussenhoven (2004, p. 1, tradução nossa) diz que "os órgãos com os quais produzimos nosso discurso, em particular a laringe, variam em tamanho de pessoa para pessoa, causando diferenças de frequência fundamental nos 
enunciados de adultos e crianças e, entre adultos, na fala de homens e mulheres".

Por isso, foi necessário transformar os dados medidos em $\mathrm{Hz}$, a fim de normalizá-los para, então, poder compará-los nos testes estatísticos. Após pesquisar qual seria a normalização ideal para esta pesquisa, optamos por usar aquela em que os dados de $\mathrm{F} 0 \mathrm{em} \mathrm{Hz}$ são convertidos para semitons (doravante st) ${ }^{7}$. Segundo Ruiz, Arantes e Rilliard, todos em comunicação pessoal com esta pesquisadora ${ }^{8}$, a normalização de $\mathrm{F} 0$ em semitons é válida porque ela é capaz de eliminar valores de frequência alterados, por exemplo, apenas por questões fisiológicas das pregas vocais.

A conversão dos valores de F0 de Hertz para semitons usa a seguinte fórmula:

\section{$\mathrm{n}=12 \times \log 2(\mathrm{fn} / \mathrm{m})$}

A fórmula é calculada numa base logarítmica de 2, em que fn é o valor em $\mathrm{Hz}$ que precisa ser convertido para semitons e $\mathbf{m}$ é a média da frequência laríngea do informante, ou seja, é a média de F0 produzida em todos os enunciados ditos pelo informante em questão.

6 "The organs, with which we produce speech, in particular the larynx, vary in size across speakers, causing differences in the fundamental frequency on adult speech and children's speech, and within adults, of male and female speech".

${ }^{7}$ A escala de semitons é uma possibilidade de derivação da escala de Hertz. Um semitom corresponde a uma frequência de $6 \%$ de diferença da escala da F0 normal (NOOTEBOOM, 1997, p. 5). O termo é bastante utilizado na música para se referir a diferentes notas sucessivas, como as do teclado de um piano em que a tecla branca, da preta imediatamente ao lado, se difere em um semitom. Uma oitava acima ou abaixo, na música, por exemplo, refere-se a 12 semitons que podem subir ou descer auditivamente falando.

${ }^{8}$ Por e-mail, indagados sobre a normalização da F0 em semitons, Pablo Arantes (em 28 jun. 2014) e Albert Rilliard (em 28 jun. 2014) disseram que esta é uma das opções possíveis. Miguel Mateo Ruiz, em uma conferência pessoal em Curitiba, em 1 de setembro de 2014, também afirmou que usar F0 em semitons é uma das possibilidades de normalização, apesar de Ruiz ter dito que não usa este tipo de normalização para os dados que pesquisa. 
Depois de converter todos os valores de $\mathrm{Hz}$ em semitons (st), passamos a rodar os testes estatísticos (explicações sobre estes testes mais adiante). Estes testes calcularão também a média do valor de F0 das sílabas nucleares de todos os enunciados, conforme a classificação de cada uma delas. Depois de obtermos a média de F0 das sílabas em análise (por categoria), faremos as duas comparações descritas na Figura 5.

No exemplo da Figura 5, compararíamos o valor médio de F0 entre as pré-tônicas da afirmativa e da declarativa ( $2.5 \mathrm{st}$ e $-2.3 \mathrm{st}$ ), entre as tônicas (4.7 st e -1.6 st) e entre as pós-tônicas das duas modalidades (3.5 st e -1.89 st). A intenção desta análise é verificar quais pontos (tônicas e/ou adjacentes) das palavras, com relação à média de F0 normalizada, trazem informações entoacionais relevantes para distinguir modalidade (afirmações de perguntas). Novamente, nessa mesma lógica foram comparados os dados de intensidade.

Para a análise dos dados de F0 em semitons normalizados, foram consideradas 1.350 produções para o núcleo, sendo:

- 252 produções de oxítonas (14 estímulos, 7 afirmativos e 7 interrogativos, $\mathrm{x} 3$ repetições $\mathrm{x} 3$ sílabas analisadas, duas pré-tônicas e a tônica, $\mathrm{x} 2$ informantes).

- 330 produções de paroxítonas. Do informante feminino foram 20 estímulos, 10 afirmativos e 10 interrogativos, x 3 repetições x 3 sílabas analisadas, pré-tônica, tônica e pós-tônica. Do informante masculino, como houve apagamento de todas as sílabas pós-tônicas paroxítonas declarativas, foram 10 estímulos afirmativos x 3 repetições x 2 sílabas analisadas (pré-tônica e tônica, porque todas as pós-tônicas apagaram) e mais 10 estímulos interrogativos x 3 repetições x 3 sílabas analisadas.

- 768 produções de proparoxítonas (32 estímulos, 16 afirmativos e 16 interrogativos, $\mathrm{x} 3$ repetições $\mathrm{x} 4$ sílabas analisadas, pré-tônica, tônica e duas pós-tônicas, x 2 informantes).

Decidimos trabalhar com a intensidade, analisando também as sílabas da região nuclear (conforme tonicidade, tipo acentual e modalidade), após conhecer uma maneira de normalizar este parâmetro, visto que utilizar a intensidade sem normalização implica em uma série de cuidados na coleta dos dados (durante a gravação) que não foram tomados por nós. 
Segundo Rilliard ${ }^{9}$, uma dificuldade de trabalhar com decibéis é que se trata de uma escala logarítmica, calculada com relação a um domínio linear, o que significa que ela não é em níveis absolutos, mas obtida a partir destes níveis de referência, ou seja, a intensidade calculada a partir de um valor expresso em decibéis não corresponde à média de um domínio linear. Isso quer dizer, então, que os níveis de intensidade são altamente sensíveis a muitos fatores incontroláveis pelo pesquisador, notadamente a distância entre o microfone e a boca, a sensibilidade do microfone utilizado, entre outras questões. Por isso, as gravações da intensidade não são comparáveis entre um informante e outro sem antes passar pela normalização (a não ser que sejam usadas rigorosas precauções a este respeito).

Por causa destes fatores e a fim de utilizar este parâmetro na comparação dos nossos dados, normalizamos a intensidade média de cada falante. Ela foi convertida, então, em uma escala linear, para ser normalizada no que diz respeito à sua média e, em seguida convertida novamente em decibéis. Para isso, duas fórmulas foram utilizadas. A primeira, para converter a intensidade em dB em uma escala linear, é a seguinte:

$$
I_{\text {linear }}=10^{\left(\frac{I_{d B}}{10}\right)} \text { ou } \mathrm{I}(\text { linear })=10^{\wedge}(\mathrm{I}(\mathrm{dB}) / 10)
$$

em que a intensidade linear é igual a 10 sob o expoente da intensidade a ser convertida em decibéis dividida por 10.

Para converter de volta para $\mathrm{dB}$, mantendo a normalização, usa-se a seguinte fórmula:

$$
\mathrm{I}(\mathrm{dB})=10 * \log 10(\mathrm{I}(\text { linear })) \text { ou } I_{d B}=10 * \log _{10}\left(I_{\text {linear }}\right)
$$

onde a medida em decibéis $(\mathbf{I}(\mathbf{d B}))$ é igual a 10 vezes o logaritmo de base 10 da intensidade linear obtida na fórmula anterior (I(linear)).

Por fim, os valores médios da intensidade normalizada de cada sílaba foram comparados da mesma maneira que o explicitado na Figura 5, ou seja, entre pré-tônicas, tônicas e pós-tônicas de afirmativas e de declarativas (conforme padrão acentual) e, depois, entre as pré-tônicas das afirmativas

${ }^{9}$ Em comunicação pessoal, via e-mail, no dia 3 de fevereiro de 2015. 
com as das interrogativas, as tônicas das afirmativas com as das interrogativas e as pós-tônicas das interrogativas com as das afirmativas.

Para a análise dos dados de intensidade normalizada, foram consideradas 1.350 produções para o núcleo, sendo:

- 252 produções de oxítonas (14 estímulos, 7 afirmativos e 7 interrogativos, $\mathrm{x} 3$ repetições $\mathrm{x} 3$ sílabas analisadas, duas pré-tônicas e a tônica, $\mathrm{x} 2$ informantes).

- 330 produções de paroxítonas. Do informante feminino foram 20 estímulos, 10 afirmativos e 10 interrogativos, x 3 repetições x 3 sílabas analisadas - pré-tônica, tônica e pós-tônica. Do informante masculino, como houve apagamento de todas as sílabas pós-tônicas paroxítonas declarativas, foram 10 estímulos afirmativos x 3 repetições x 2 sílabas analisadas (pré-tônica e tônica porque todas as pós-tônicas apagaram) e mais 10 estímulos interrogativos x 3 repetições x 3 sílabas analisadas.

- 768 produções de proparoxítonas (32 estímulos, 16 afirmativos e 16 interrogativos, $\mathrm{x} 3$ repetições $\mathrm{x} 4$ sílabas analisadas, pré-tônica, tônica e duas pós-tônicas, $\mathrm{x} 2$ informantes).

Ao todo, observamos 2.700 sílabas nesta análise de produção (1.350 sílabas com dados de F0 e 1.350 sílabas com dados de intensidade).

\section{Testes Estatísticos}

Analisamos estatisticamente os dados de F0 média normalizada e da intensidade a partir do programa SPSS 18.

Com o intuito de testar se a diferença é significativa ( $p<G$ 0.05) entre os valores médios (de F0 e da intensidade - cada parâmetro por vez) entre as modalidades declarativa e interrogativa conforme tonicidade (pré-tônicas com pré-tônicas, tônicas com tônicas e pós-tônicas com pós-tônicas) e segundo padrão acentual (oxítonas, paroxítonas e proparoxítonas) utilizamos o Teste $\mathrm{T}$ de Variáveis Independentes para a comparação entre dois instrumentos. 


\section{Resultados da F0}

Começaremos mostrando os gráficos e descreveremos brevemente as curvas para, depois, apontar as análises estatísticas referentes aos valores médios de F0 de cada modalidade e padrão acentual (primeiramente, os dados do informante feminino e, depois, os do masculino). Iniciaremos pelas oxítonas na região nuclear.

\section{Oxítonas}

O Quadro 1 mostra que a região nuclear com oxítonas (bisavô, nadador e Salvador) é semelhante para os dois informantes nas sílabas pré-tônicas, porém, há uma diferenciação nas tônicas: o informante feminino costuma fazer a F0 das tônicas das interrogativas mais alta que as das tônicas das declarativas (por isso os gráficos se cruzam), diferentemente do informante masculino.

Quadro 1 - Contorno do núcleo oxítono dos dados dos informantes feminino e masculino

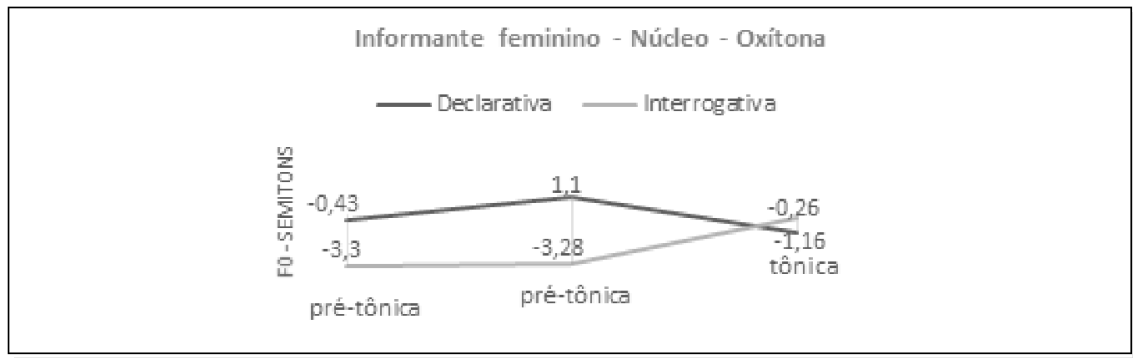

Fonte: Amper-Por.

Nota: Declarativas estão em cinza escuro e interrogativas em cinza claro. Os valores que aparecem nos gráficos referem-se à média de $\mathrm{F} 0$ de cada sílaba (identificadas com os nomes de pré-tônica, tônica e pós-tônica) em semitons normalizados. 
Na região nuclear, a curva que fica com o formato de "chapéu invertido" é o das interrogativas e a que fica com o chapéu em formato de acento circunflexo é o das declarativas. Isso nos permite afirmar que o formato da curva entoacional muda conforme o ambiente em que as oxítonas estão.

O Teste T de Variáveis Independentes mostra que as médias de F0 dos pares das sílabas entre declarativas e interrogativas é diferente estatisticamente (as sílabas das declarativas têm valores significativamente maiores que as das interrogativas): (a) a primeira pré-tônica $(-0,43 \mathrm{st})$ com a primeira pré-tônica $(-3,30 \mathrm{st})(\mathrm{t}(34)=6,623, \mathrm{p}=0,000)$ para a mulher e a primeira pré-tônica $(0,069 \mathrm{st})$ com primeira pré-tônica $(-6,18 \mathrm{st})(\mathrm{t}(34)=$ 13.236, $\mathrm{p}=0,000)$ para o homem; (b) a segunda pré-tônica $(1,10 \mathrm{st})$ com a segunda pré-tônica $(-3,28 \mathrm{st})(\mathrm{t}(34)=15,157, \mathrm{p}=0,000)$ para a mulher e a segunda pré-tônica $(2,84 \mathrm{st})$ com a segunda pré-tônica $(-5,86 \mathrm{st})(\mathrm{t}(34)=$ $12,226, \mathrm{p}=0,000)$ para o homem; (c) a tônica $(-1,16 \mathrm{st}$ ) com a tônica $(-0,26 \mathrm{st})(\mathrm{t}(34)=-2,374=\mathrm{p}=0,023)$ para a mulher e a tônica $(1,75 \mathrm{st}) \mathrm{com}$ a tônica $(-0,12$ st) (t $(34)=3,262, \mathrm{p}=0,003)$ para o homem. Na questão perceptiva, seria possível perceber auditivamente a diferença da segunda prétônica das interrogativas para a declarativas (sobe 4,38 st) do informante feminino - lembrando que 3 semitons (st) ou mais são perceptíveis como diferentes ao ouvido humano, conforme estudo de Milan (2015). Nos dados do informante masculino, seria perceptível auditivamente a mudança da primeira pré-tônica da interrogativa para a declarativa (que sobe 6,24 st) e da segunda pré-tônica (aumenta 8,64 st). Neste caso, a diferença da F0 da interrogativa para a declarativa (tanto do homem quanto da mulher) das tônicas não seria perceptível auditivamente, porque a diferença é menor do que 3 st, o que nos leva a afirmar que, nas oxítonas nucleares, os valores médios de F0 das pré-tônicas desempenham o papel de diferenciação entre modalidades, apesar de os valores médios das tônicas terem sido significativamente diferentes.

\section{Paroxítonas}

Nas paroxítonas nucleares (Renato, pateta e Veneza), enfrentamos um problema na análise dos dados porque o informante masculino apagou todas 
as pós-tônicas das declarativas ${ }^{10}$, o que inviabilizou a comparação fiel dos dados entre os dois informantes e entre as sílabas desta modalidade. Mesmo assim, vejamos o Quadro 2:

Quadro 2 - Contorno do núcleo paroxítono dos dados dos informantes feminino e masculino

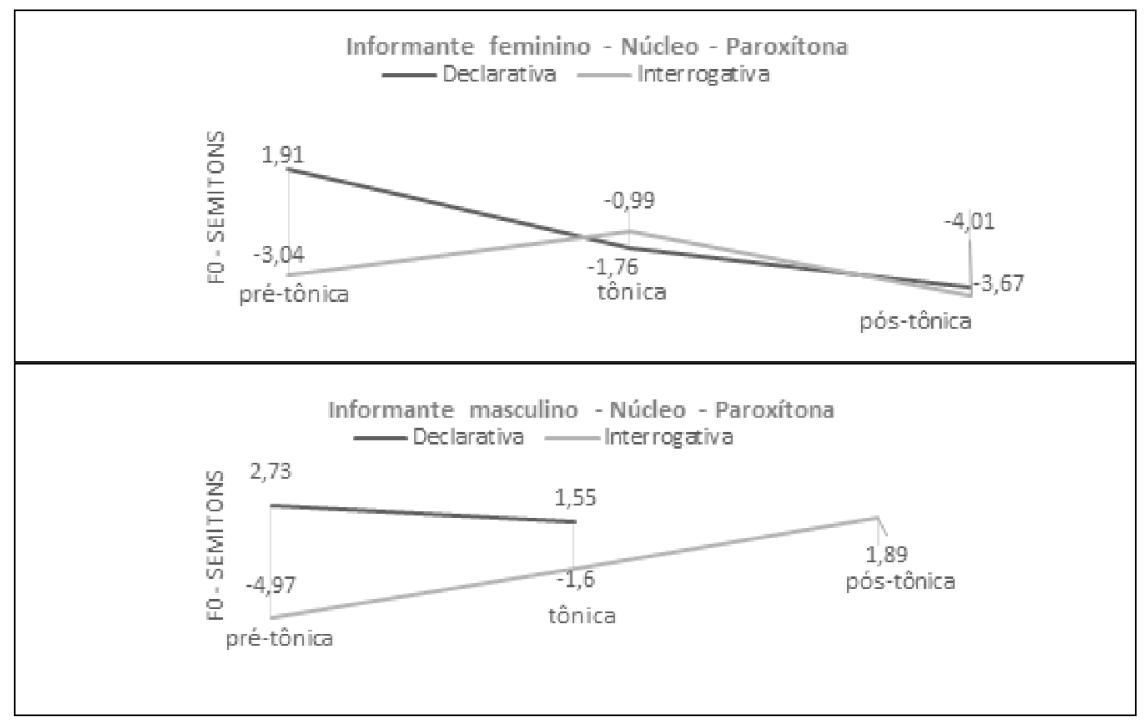

Fonte: Amper-Por.

Nota: Declarativas estão em cinza escuro e interrogativas em cinza claro. Os valores que aparecem nos gráficos referem-se às médias de F0 de cada sílaba (identificadas com os nomes de pré-tônica, tônica e pós-tônica) em semitons normalizados.

${ }^{10}$ Não podemos afirmar categoricamente, com o número de informantes que dispomos nesta pesquisa, que falantes do dialeto de Curitiba tendem a fazer apagamentos das pós-tônicas finais, porém observamos isso em todas as pós-tônicas do informante masculino na modalidade declarativa paroxítona. Interessante notar que Silva (2011) também teve um informante de Curitiba, neste caso do sexo feminino, que apagou todas as pós-tônicas finais, mas das interrogativas (também dos núcleos paroxítonos). Talvez estes apagamentos das pós-tônicas podem ser referentes ao modo de falar do curitibano, porém, uma pesquisa focada apenas nisso se faz necessário para afirmar isso com rigor científico. 
As declarativas apresentam um movimento de queda (da pré-tônica até a pós-tônica) nos dados do informante feminino e parecem seguir esta mesma tendência para os dados do informante masculino (apesar de não ser possível afirmar isso categoricamente em decorrência dos apagamentos das pós-tônicas). Nas interrogativas, percebemos o movimento circunflexo da F0 para o informante feminino e de ascensão para o informante masculino.

$\mathrm{O}$ Teste $\mathrm{T}$ de Variáveis Independentes mostra que apenas os valores do par das pré-tônicas são diferentes entre si $(t(58)=15,794$, p $=0,000)$ - as médias de F0 das declarativas (1,91 st) são maiores do que as das interrogativas (-3,04 st). Ou seja, apenas a F0 das pré-tônicas (das declarativas e das interrogativas) marcaria a diferença, no núcleo, entre modalidades das paroxítonas para os dados do informante feminino. Auditivamente, somente a diferença média de F0 também da pré-tônica das interrogativas para a das declarativas (sobe 4,95 st) seria percebida ao ouvido humano, o que nos levar a indicar que, nos dados do informante feminino, a pré-tônica marcaria a diferença de modalidade.

São diferentes também os valores dos pares de pré-tônicas do informante masculino (2,73 st das declarativas e $-4,97$ st das interrogativas) $(\mathrm{t}(52)=16,529, \mathrm{p}=0,000)$ e os pares das tônicas $(1,55 \mathrm{st}$ das declarativas e $-1,60$ st das interrogativas) ( $\mathrm{t}(58)=5,765, \mathrm{p}=0,000)$ - ou seja, as médias de F0 das declarativas são significativamente maiores que as das interrogativas. Os pares das pós-tônicas do informante masculino não serão comparados porque temos apenas dados das pós-tônicas das interrogativas (todas as pós-tônicas das declarativas apagaram). Auditivamente, seriam percebidas como diferentes, segundo Milan (2015), a pré-tônica da interrogativa com relação à declarativa (sobe $7,7 \mathrm{st}$ ) e a tônica da interrogativa com relação à declarativa (sobe 3,15 st) para os dados do informante masculino.

Nos núcleos paroxítonos, podemos perceber uma tendência de as médias de F0 das pré-tônicas marcarem a distinção entre modalidades, assim como nas oxítonas, apesar de que, nos dados do informante masculino, os valores das tônicas também fariam este papel.

\section{Proparoxítonas}

Sobre as proparoxítonas nucleares (pássaro, bêbado e Mônaco), vejamos o Quadro 3: 


\section{Quadro 3 - Contorno do núcleo proparoxítono dos dados dos informantes feminino e masculino.}

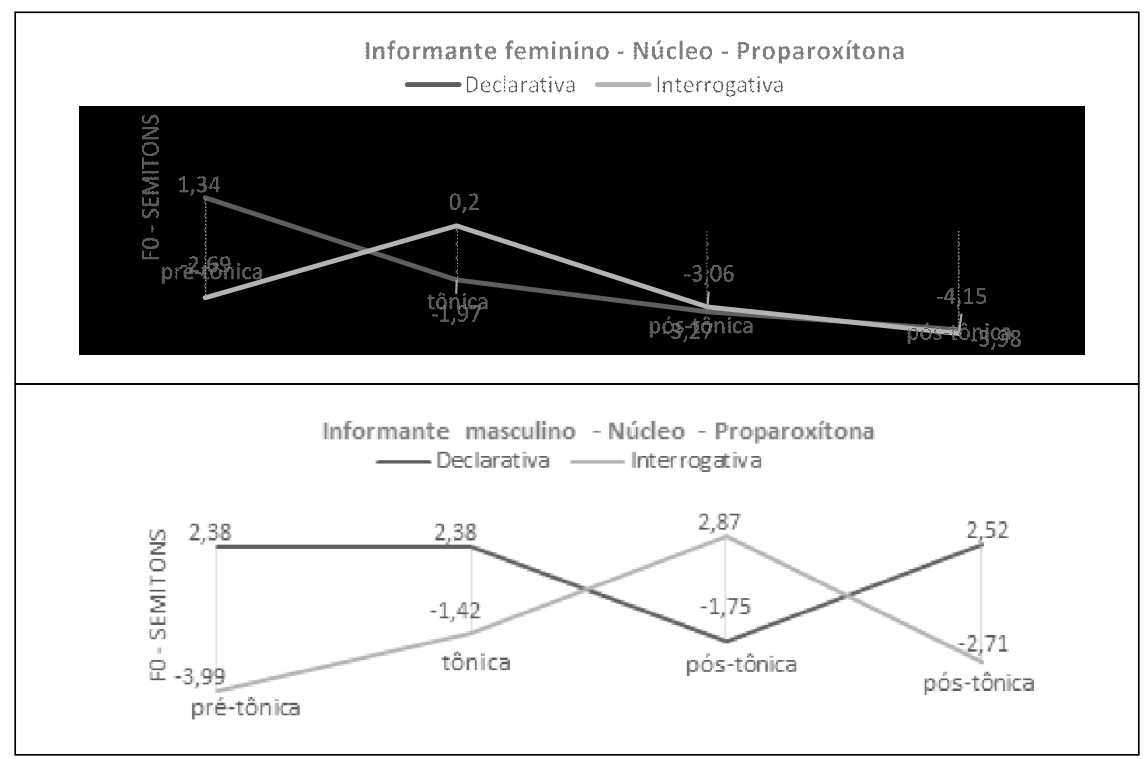

Fonte: Amper-Por.

Nota: Declarativas estão em cinza escuro e interrogativas em cinza claro. Os valores que aparecem nos gráficos referem-se à média de $\mathrm{F} 0$ de cada sílaba (identificadas com os nomes de pré-tônica, tônica e pós-tônica) em semitons normalizados

Enquanto a curva melódica do informante feminino tem o pico das interrogativas na tônica e o das declarativas na pré-tônica, o do masculino faz os picos das curvas - tanto das declarativas como das interrogativas nas pós-tônicas.

Com relação aos testes estatísticos, o Teste T de Variáveis Independentes reportou diferenças entre os valores dos pares de pré-tônicas (1,34 st para as declarativas e -2,69 st para as interrogativas) $(\mathrm{t}(94)=16,242, \mathrm{p}=0,000) \mathrm{e}$ das tônicas $(-1,97$ st para as declarativas e 0,20 st para as interrogativas) $(\mathrm{t}(100)=-8,907, \mathrm{p}=0,000)$ para os dados do informante feminino. Os valores dos demais pares não são significativamente diferentes entre si (nestes pontos, é possível perceber, nos gráficos, que as linhas das curvas entoacionais 
quase que se alinham nas duas modalidades). Auditivamente, seria perceptível ao ouvido humano apenas a diferença entre a pré-tônica da interrogativa para a pré-tônica da declarativa (sobe 4,03 st).

Nos dados do informante masculino, o Teste $\mathrm{T}$ de Variáveis Independentes reportou diferença significativa entre todos os valores dos pares das duas modalidades (respectivamente declarativas e interrogativas): (a) pré-tônica (2,38 st) com pré-tônica (-3,99 st) ( $\mathrm{t}(61)=8,648, \mathrm{p}=0,000)$; (b) tônica $(2,38 \mathrm{st})$ com tônica $(-1,42 \mathrm{st})(\mathrm{t}(100)=9,981, \mathrm{p}=0,000)$; (c) primeira pós-tônica $(-1,75 \mathrm{st})$ com primeira pós-tônica $(2,87 \mathrm{st})(\mathrm{t}(46)=$ $-3,258, \mathrm{p}=0,002)$ e; (d) da segunda pós-tônica (2,52 st) com a segunda póstônica $(-2,71 \mathrm{st})(\mathrm{t}(25)=2,567, \mathrm{p}=0,017)$. Auditivamente, também seriam percebidas como diferentes todas as sílabas de uma modalidade para a outra: da pré-tônica da interrogativa para a pré-tônica da declarativa sobe 6,37 st; da tônica sobe 3,80 st, da primeira pós-tônica da declarativa para a primeira pós-tônica da interrogativa sobe 4,62 st e, por fim, da segunda pós-tônica da interrogativa para a da declarativa sobe 5,23 st.

Para facilitar a compreensão da análise dos dados, resumimos o que foi encontrado até aqui. Podemos afirmar que os valores das pré-tônicas nucleares (sejam as duas ou apenas uma delas) são sempre significativamente diferentes entre modalidades e que pelo menos uma delas (se não as duas) são perceptíveis auditivamente como diferentes, não importando o padrão acentual (oxítona, paroxítona ou proparoxítona). A F0 das tônicas também é significativamente diferente entre as modalidades, com exceção das tônicas paroxítonas do informante feminino. Já o valor das pós-tônicas só é significativamente diferente - entre modalidades - nas proparoxítonas do informante masculino, e apenas neste caso, também são perceptíveis auditivamente como diferentes.

\section{Resultados da Intensidade}

A partir de agora, trataremos do parâmetro acústico intensidade, comparando sílabas da mesma maneira pela qual já explicamos anteriormente, conforme padrão acentual (oxítona, paroxítona e proparoxítona), tonicidade (pré-tônicas, tônicas, pós-tônicas) e modalidade (declarativas e interrogativas). Apresentaremos, primeiramente, os dados do informante feminino e, depois, os do masculino. 


\section{Oxítonas}

O Quadro 4 compara a intensidade média das sílabas de palavras oxítonas (bisavô, nadador e Salvador) segundo a tonicidade (duas pré-tônicas e tônica) e por modalidade: o cinza mais escuro é o gráfico das declarativas e o mais claro é o das interrogativas.

Quadro 4 - Valor médio da intensidade, normalizada, do núcleo oxítono dos dados dos informantes feminino e masculino.

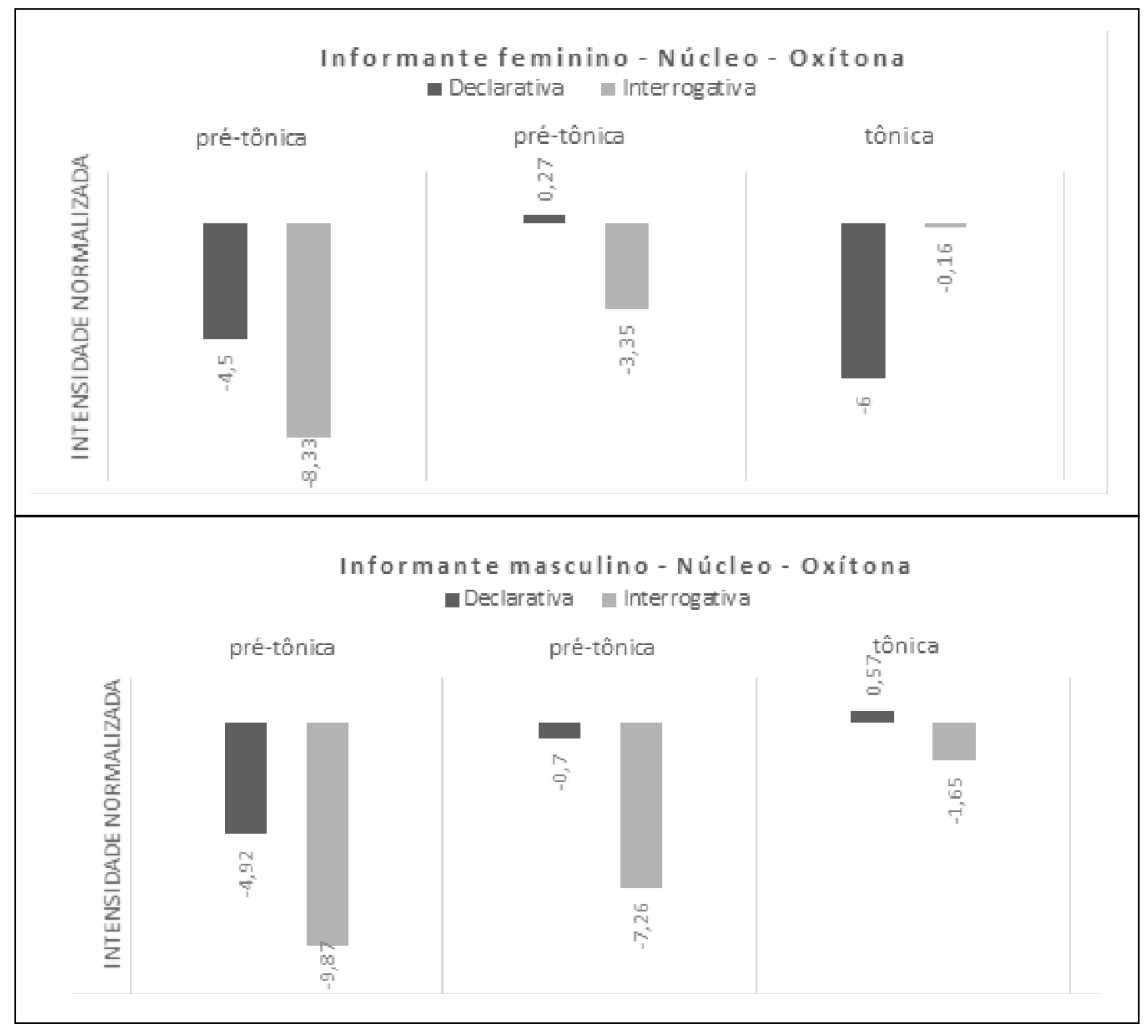

Fonte: Amper-Por.

Nota: Declarativas estão em cinza escuro e interrogativas em cinza claro. Os valores que aparecem nos gráficos referem-se à média de intensidade de cada sílaba (identificadas com os nomes de pré-tônica, tônica e pós-tônica). 
Podemos notar que, nos núcleos oxítonos, as primeiras pré-tônicas costumam hospedar a intensidade mais acentuada (negativamente), maior, inclusive, do que nas tônicas (com exceção da tônica da declarativa do informante feminino). Isso demonstra que nem sempre o acento lexical da palavra está correlacionado com uma intensidade mais elevada. E, na comparação entre modalidades, as interrogativas costumam ter nas sílabas uma intensidade maior do que nas declarativas. Este aspecto já foi apontado por Reis (1995 apud ANTUNES, 2007, p. 66), de que, nas assertivas, os valores de intensidade diminuem desde o início, o que não ocorre com as interrogativas.

$\mathrm{Na}$ comparação entre modalidades, o Teste $\mathrm{T}$ de Variáveis Independentes apontou que, nos dados do informante feminino, todos os pares são significativamente diferentes com relação aos dados de intensidade: (a) primeira pré-tônica $(-4,50 \mathrm{~dB})$ com primeira pré-tônica $(-8,33 \mathrm{~dB})(\mathrm{t}$ (34) $=2,355, \mathrm{p}=0,024)$, (b) segunda pré-tônica $(0,27 \mathrm{~dB})$ com segunda pré-tônica $(-3,55 \mathrm{~dB})(\mathrm{t}(34) 5,438, \mathrm{p}=0,000)$ e (c) tônica $(-6 \mathrm{~dB})$ com tônica $(-0,16 \mathrm{~dB})(\mathrm{t}(34)=-2,948, \mathrm{p}=0,006)$. O informante masculino, com relação à intensidade entre modalidades, produziu valores diferentes para os pares de sílabas das primeiras pré-tônicas $(-4,92 \mathrm{~dB}$ para as declarativas e -9,87 dB para as interrogativas) ( $\mathrm{t}(34)-2,699, \mathrm{p}=0,011)$ e das segundas pré-tônicas $(-0,70 \mathrm{~dB}$ para as declarativas e $-7,26 \mathrm{~dB}$ para as interrogativas) $(\mathrm{t}(34)=$ $5,322, p=0,000)$. Importante ressaltar que o informante masculino não faz diferenciação de modalidade, no núcleo oxítono, pela intensidade nas tônicas e, sim, nas pré-tônicas.

\section{Paroxítonas}

Nos núcleos paroxítonos (Renato, pateta e Veneza), o informante feminino produziu as maiores intensidades na pós-tônica e, o masculino, na pré-tônica e na pós-tônica. Como o informante masculino apagou as pós-tônicas das declarativas com núcleo paroxítono, mais uma vez encontramos dificuldades de comparar os dados neste ambiente. Vejamos o Quadro 5: 
Quadro 5 - Valor médio da intensidade, normalizada, do núcleo paroxítono dos dados dos informantes feminino e masculino

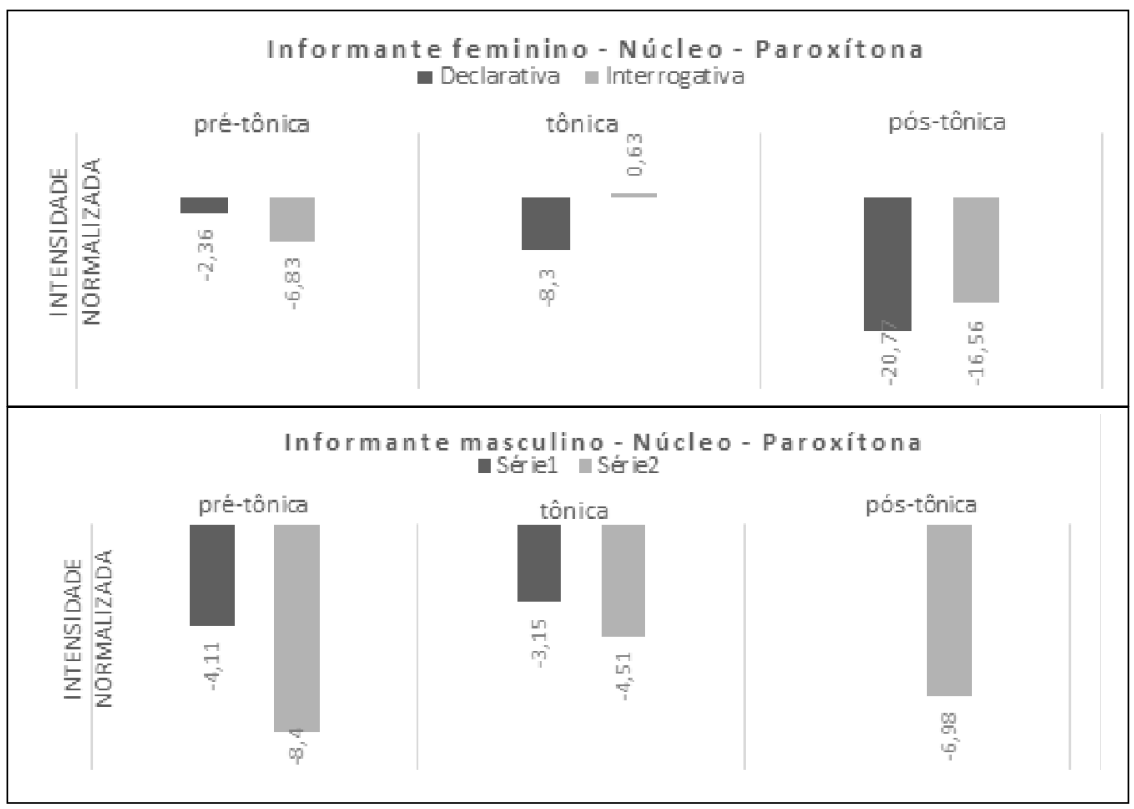

Fonte: Amper-Por.

Nota: Declarativas estão em cinza escuro e interrogativas em cinza claro. Os valores que aparecem nos gráficos referem-se à média de intensidade de cada sílaba (identificadas com os nomes de pré-tônica, tônica e pós-tônica).

O Teste T de Variáveis Independentes mostrou que a intensidade é diferente entre todos os pares de sílabas nos dados da mulher: (a) pré-tônica $(-2,36 \mathrm{~dB})$ com pré-tônica $(-6,83 \mathrm{~dB})$, respectivamente da declarativa para a interrogativa $(\mathrm{t}(58)=3,394, \mathrm{p}=0,001)$, tônica $(-8,30 \mathrm{~dB})$ com tônica $(0,63$ $\mathrm{dB})(\mathrm{t}(58)=-11,746, \mathrm{p}=0,000)$ e pós-tônica $(-20,77 \mathrm{~dB})$ com pós-tônica $(-16,56 \mathrm{~dB})(\mathrm{t}(37)=-2,176, \mathrm{p}=0,036)$. Nas intensidades dos dados do homem, como as pós-tônica das declarativas com núcleo paroxítono foram apagadas, só foi possível comparar as pré-tônicas e as tônicas e, o Teste T de Variáveis Independentes apontou diferença significativa nas intensidades das sílabas pré-tônicas $(-4,11 \mathrm{~dB})$ das declarativas em relação às interrogativas 
$(-8,40 \mathrm{~dB})(\mathrm{t}(52)=4,534, \mathrm{p}=0,000)$ e das tônicas $(-3,15 \mathrm{~dB}$ para as declarativas e $-4,51 \mathrm{~dB}$ para as interrogativas) $(\mathrm{t}(58)=1,982, \mathrm{p}=0,052)$.

\section{Proparoxítonas}

Nos núcleos proparoxítonos (pássaro, bêbado e Mônaco), as intensidades médias das sílabas do informante feminino tendem a ser maiores nas pós-tônicas (tanto das declarativas como das interrogativas). Nas sílabas realizadas pelo homem, a intensidade das sílabas tônicas e pós-tônicas ficam bastante semelhantes e o que varia mais é a intensidade das pré-tônicas e das segundas pós-tônicas. Vejamos o Quadro 6:

Quadro 6 - Valor médio da intensidade, normalizada, do núcleo proparoxítono dos dados dos informantes feminino e masculino

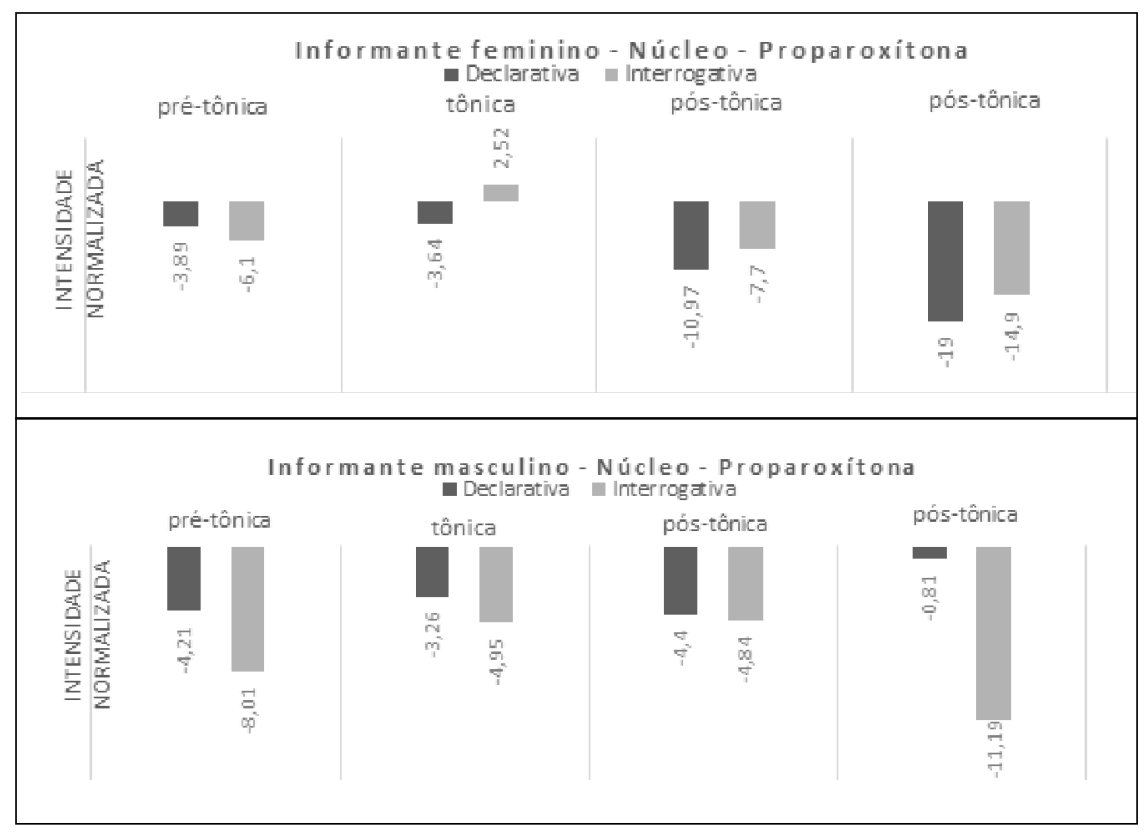

Fonte: Amper-Por

Nota: Declarativas estão em cinza escuro e interrogativas em cinza claro. Os valores que aparecem nos gráficos referem-se à média de intensidade de cada sílaba (identificadas com os nomes de pré-tônica, tônica e pós-tônica). 
Nos dados do informante feminino, todos os valores dos pares entre modalidades são significativamente diferentes quanto à intensidade: (a) pré-tônicas $(-3,89 \mathrm{~dB}$ para as declarativas e $-6,10 \mathrm{~dB}$ para as interrogativas) entre si ( $\mathrm{t}(94)=3,022, \mathrm{p}=0,003)$, (b) tônicas entre si $(-3,64 \mathrm{~dB}$ para as declarativas e 2,52 dB para as interrogativas) ( $\mathrm{t}(100)=-9,101, \mathrm{p}=0,000)$, (c) primeiras pós-tônicas entre si $(-10,97 \mathrm{~dB}$ para as declarativas e $-7,70 \mathrm{~dB}$ para as interrogativas) $(\mathrm{t}(94)=-4,525, \mathrm{p}=0,000)$ e $(\mathrm{d})$ segundas pós-tônicas entre si $(-19 \mathrm{~dB}$ para as declarativas e $-14,9 \mathrm{~dB}$ para as interrogativas) $(\mathrm{t}(97)=$ $-5,064, \mathrm{p}=0,000)$. Nos dados do informante masculino, apenas os valores de intensidade das primeiras pós-tônicas não são significativamente diferentes $(\mathrm{t}(46)=0,331, \mathrm{p}=0,742)$. Nos demais casos, a diferença é significativa: respectivamente para as declarativas e interrogativas (a) pré-tônica $(-4,21 \mathrm{~dB})$ com pré-tônica $(-8,01 \mathrm{~dB})(\mathrm{t}(61)=2,900, \mathrm{p}=0,005)$, (b) tônica $(-3,26 \mathrm{~dB})$ com tônica $(-4,95 \mathrm{db})(\mathrm{t}(100)=2,119, \mathrm{p}=0,037)$ e (c) segunda pós-tônica $(-0,81 \mathrm{~dB})$ com segunda pós-tônica $(-11,19 \mathrm{~dB})(\mathrm{t}(25)=2,906, \mathrm{p}=0,008)$.

Resumidamente, podemos afirmar que a intensidade é um parâmetro acústico que ajuda a distinguir modalidades, conforme já apontaram autores como Nunes $(2011,2013)$, em que as tônicas das interrogativas de Florianópolis tiveram maior intensidade do que as sílabas vizinhas, ou conforme Reis (1995 apud ANTUNES, 2007), em que a intensidade das assertivas diminuiu desde o início, o que não ocorre com as interrogativas. Apesar disso, importante relembrar que Costa e Cruz (2013) não encontraram na intensidade uma diferenciação entre modalidades.

Informantes de nossa pesquisa evidenciam, para o dialeto de Curitiba, a tendência de que a intensidade pode distinguir modalidades: a diferença de valor é significativa nas pré-tônicas das oxítonas (bisavô, nadador e Salvador) da declarativa para a interrogativa, nas pré-tônicas e tônicas das paroxítonas (Renato, pateta e Veneza) e nas pré-tônicas, tônicas e últimas pós-tônicas das proparoxítonas (pássaro, bêbado e Mônaco).

\section{Conclusões}

Os parâmetros acústicos F0 e intensidade têm um papel importante na distinção de interrogativas totais e afirmativas neutras no dialeto curitibano. Sobre a F0 podemos afirmar que os valores das pré-tônicas nucleares (sejam as duas ou apenas uma delas) são sempre significativamente diferentes entre 
modalidades e que pelo menos uma delas (se não as duas) são perceptíveis auditivamente como diferentes. A F0 das tônicas também é significativamente diferente entre as modalidades, com exceção das tônicas paroxítonas do informante feminino. Já o valor das pós-tônicas só é significativamente diferente - entre modalidades - nas proparoxítonas do informante masculino e, apenas neste caso, também, são perceptíveis auditivamente como diferentes.

Os dados do falar de Curitiba mostraram ainda que a intensidade manteve padrões diferentes entre declarativas e interrogativas, por isso este parâmetro acústico pode ajudar a distinguir modalidades. O valor da intensidade é significativo nas pré-tônicas das oxítonas da declarativa para a interrogativa, nas pré-tônicas e tônicas das paroxítonas (entre as duas modalidades) e nas pré-tônicas, tônicas e últimas pós-tônicas das proparoxítonas (também entre as sílabas das duas modalidades).

\section{Referências}

ANTUNES, L. B. O papel da prosódia na expressão de atitudes do locutor em questões. 2007. Tese (Doutorado em Estudos Linguísticos) - Universidade Federal de Minas Gerais, Belo Horizonte.

BOLINGER, D. Around the edge of language: intonation. In:

BOLINGER, D. (Ed.). Intonation. Inglaterra: Great Britain, 1972. p. 19-29.

COSTA, M. S. da S.; CRUZ, R. C. F. Contribuições para o atlas do Projeto AMPER - Norte: variedade linguística de Mocajuba (PA). In: SEMINÁRIO DE PESQUISAS EM ANDAMENTO - Sepa, 10., 2013, Belém. Anais... Belém: Programa de Pós-Graduação em Letras da UFPA, 2013.

CRYSTAL, D. The English tone of voice: essays in intonation, prosody and paralanguage. Londres: Edward Arnold, 1975.

FÓNAGY, I. As funções modais da entoação. Cadernos de Estudos Lingüisticos, Campinas, p. 25-65, jul./dez. 1993.

GUSSENHOVEN, C. The phonology of tone and intonation. Nova York: Cambridge University Press, 2004. 
HIRST, D. J.; DI CRISTO, A. Intonation systems: a survey of twenty languages. Cambridge: Cambridge University Press, 1998.

LADD, D. R. Intonational phonology. 2. ed. New York: Cambridge University Press, 2008. (Cambridge Studies in Linguistics, 79).

LADEFOGED, P.; JOHNSON, K. A course in phonetics. 6. ed. Boston: Wadsworth; Cengage Learning. 2006.

MILAN, P. Subsidios para uma análise prosódica do dialeto de Curitiba: uma contribuição ao projeto Amper-Por. 2015. Dissertação (Mestrado em Linguística) - Universidade Federal do Paraná, Curitiba.

MORAES, J. A. The pitch accents in Brazilian Portuguese: analysis by synthesis. Fourth Conference on Speech Prosody. Campinas: Unicamp, 2008. p. 389-397.

NOOTEBOOM, S. G. The prosody of speech: Melody and rhythm. In: HARDCASTLE, W. J.; LAVER, J. The handbook of phonetics sciences. Oxford: Black Well Publishers, 1997.

NUNES, V. Análises entoacionais de sentenças declarativas e interrogativas totais nos falares florianopolitano e lageano. 2011. Dissertação (Mestrado em Linguística) - Universidade Federal de Santa Catarina, Florianópolis.

NUNES, V. Características entoacionais de sentenças interrogativas totais em falares catarinenses e sergipanos. 2013. Qualificação (Doutorado em Linguística) Universidade Federal de Santa Catarina, Florianópolis.

PROJETO AMPER-POR. Disponível em: <http://bit.ly/2kn6V6M>.

SILVA, J. C. B. Caracterização prosódica dos falares brasileiros: as orações interrogativas totais. 2011. Dissertação (Mestrado em Letras Vernáculas) Universidade Federal do Rio de Janeiro, Rio de Janeiro.

Recebido em: 09/04/2016

Aceito em: 28/08/2016 